\title{
RELAÇÃO CONJUGAL, VIOLÊNCIA PSICOLÓGICA E COMPLEMENTARIDADE FUSIONAL
}

\author{
Lidia Levy* \\ Isabel Cristina Gomes**
}

Resumo

Neste artigo abordamos um tipo específico de dinâmica conjugal marcada pela violência psicológica. Na clínica com casais, temos observado situações nas quais são utilizadas agressóes verbais e humilhações, que afetam a auto-estima e a capacidade de reação e decisão da pessoa agredida. Forma-se um laço perverso caracterizado por um movimento recíproco no sentido do domínio do parceiro, com condiçōes e exigências que submetem a ambos, levando a um tipo de relação na qual impera a complementaridade fusional. $\mathrm{O}$ discurso característico da contemporaneidade, de obtenção de prazer e busca da perfeição nos relacionamentos amorosos e da presença do modelo igualitário nas relações homem/ mulher, põe em destaque esse tipo de dinâmica relacional. Observa-se, em alguns casos, uma fixação do modelo "homem-ativo-fálico/mulher-passiva-castrada" que permanece subjacente à mudança dos tempos.

Palavras-chave: relação conjugal; violência psicológica; complementaridade fusional.

\section{Abstract \\ CONJUGAL RELATIONSHIP, PSYCHOLOGICAL VIOLENCE AND FUSIONAL COMPLEMENTARITY}

In this article we approach a specific type of conjugal dynamic that is marked by psychological violence. In our clinical work with couples, we have noticed situations in which verbal aggressions and humiliations are used, influencing the self-esteem and the reaction capacity of the person who suffered the aggression. A perverse bond takes form, characterized by a reciprocal

* Professora do Departamento de Psicologia da Pontifícia Universidade Católica do Rio de Janeiro (PUC-Rio).

** Professora Associada do Departamento de Psicologia Clínica do Instituto de Psicologia da Universidade de São Paulo (USP). 
movement towards dominating one's partner with conditions and demands that subjugate both of them, leading to a type of relationship where a fusional complementarity rules. The typical discourse of the contemporaneousness, concerning the attainment of pleasure, the search for perfection in love relationships and the presence of the equalitarian man/woman relationship model, highlights this kind of relational dynamics. In some cases, one observes the fixing of the "phallic-active-man/castrated-passive-woman" model that remains concurrent to the changing of times.

Keywords: conjugal relationship; psychological violence; fusional complementarity.

Na clínica com casais, temos observado situações nas quais ocorrem agressões verbais e humilhações, que afetam a auto-estima e a capacidade de reação e decisão da pessoa agredida. A violência psicológica entre cônjuges contribui para a manutenção de uma relação de total desqualificação do outro e para a formação de um laço perverso caracterizado por um movimento recíproco no sentido do domínio do parceiro, com condições e exigências que submetem a ambos. Considerando relações conjugais marcadas por investimentos narcísicos, voltaremos nossa atenção para a violência psicológica decorrente de um movimento sádico que visa atingir e desestruturar o narcisismo do parceiro.

Encontramos na clínica com casais, na cidade do Rio de Janeiro, uma dinâmica relacional que adquire características de laço perverso. São casos nos quais existe, por um lado, um homem desempregado ou vivendo um fracasso no gerenciamento de sua vida profissional. Por outro lado, a parceira feminina ou manteve seu status profissional ou obteve algum tipo de promoção, transformando-se em provedora da vida familiar. A perda fálica do marido gera, após algum tempo em que este se manteve imobilizado, críticas e queixas constantes de sua esposa. Neste cenário, observa-se uma reação do parceiro, talvez circunscrita a uma realidade típica da cidade em questão, que mostra seus efeitos na vida sexual dos casais. A mulher reclama da perda de desejo apresentada pelo marido e cobra deste a falta de desempenho na cama. Curiosamente, em diferentes casais atendidos, os maridos reagem de forma semelhante diante da queixa feminina: "Não dá para ter tesão numa mulher gorda, você tinha que fazer algum esforço para emagrecer”.

Vale aqui ressaltar que na cidade do Rio de Janeiro, por suas características peculiares, cidade litorânea e turística, a exposição cotidiana do corpo feminino é mais intensa. Logo, a ênfase numa "estética corporal", típica da contemporaneidade que valoriza o individualismo e o consumismo e que associa o amor a uma habilidade a ser desenvolvida ou adquirida, à semelhança das mercadorias (Bauman, 
2004), atinge um grau de exigência que leva as mulheres a buscarem uma perfeição corporal, conseguida, muitas vezes, às custas da "malhação do corpo" nas academias ou "esculpindo" o corpo pelas cirurgias plásticas. Daí, qualquer comentário que demonstre estar sendo vista ou definida fora desses padrōes poderá assumir uma característica agressiva e, quando o comentário for proveniente do parceiro, será sentido como um violento ataque à sua pessoa.

Para o homem, até bem recentemente único responsável pela manutenção da família, sua auto-imagem sempre esteve muito ligada ao trabalho. O poder que antes se concentrava apenas na figura masculina foi redistribuído, de modo que a entrada da mulher no mercado de trabalho ocasionou algumas perdas significativas no lugar até então por aquele ocupado. Foi necessário aprender a conviver com uma mulher que passou a ser sua concorrente e defrontou-se com a questão do desemprego. $\mathrm{O}$ desemprego não causa apenas a perda do poder aquisitivo nas famílias, mas afeta profundamente a auto-imagem do homem, gerando muitas vezes conseqüências individuais graves e problemas na relação conjugal. Verificamos na população brasileira que homens e mulheres têm tido dificuldades em lidar com situaçóes nas quais ele perde o papel de provedor do lar ou naquelas em que a esposa acaba ganhando mais do que o marido.

Gomes (2001) aponta como o trabalho possibilitou às mulheres um caminho alternativo para sua ascensão social, antes só possível pelo casamento, e adquiriu uma conotação de realização pessoal e elevação da auto-imagem. Entretanto, na última década, a nossa sociedade vem empobrecendo. A mulher se consolidou no mercado de trabalho, porém hoje ela precisa trabalhar não mais apenas por auto-realização. A família empobreceu e o homem perdeu o seu status de único provedor. A autora observa que algumas mulheres, principalmente aquelas que têm uma carreira, sentem-se culpadas (por terem um emprego), estranhas, às vezes frágeis, e até exploradas por esses homens, mesmo quando são capazes de continuar promovendo o sustento de suas famílias. Em contraposição, alguns homens deprimem-se e perdem sua auto-estima. Considerando que sua identidade e auto-imagem estiveram associadas ao trabalho que desempenhavam e ao dinheiro que recebiam, diante do desemprego, enfraquecem, desmoronam e sentem dificuldade em conviver com a mudança de papéis na família. Frente a este marido fragilizado, a mulher vê nele espelhada toda a sua fragilidade e ressente-se pela impossibilidade de realização da fantasia de ser cuidada pelo provedor.

A mulher pós-Feminismo, presa às suas raízes sócio-históricas, vive uma situação ambivalente: espera construir uma relação conjugal de dupla renda, ao mesmo tempo que mantém estereótipos sociais do passado. Algumas descrições freqüentes relativas ao modelo ideal de masculinidade apontam para um homem 
que deveria ser "forte, confiante, ativo, destemido, determinado, realizador, independente, objetivo, pragmático, racional, emocionalmente equilibrado, profissionalmente competente, financeiramente bem-sucedido e sexualmente impositivo" (Wang, Jablonski \& Magalhães, 2006: 2).

Simultaneamente, o discurso sobre a mulher precisou ser repensado, as certezas que cercavam o espaço destinado ao homem, conseqüentemente, foram questionadas e abaladas. As antigas ilusões sobre a vida conjugal, os ideais de homem e mulher presentes no imaginário social ganham novas feições. Papéis e tarefas já não mais indicam diferenças entre homens e mulheres. Ao perceberem que não precisavam dos homens para produzir sua subsistência, as mulheres viram-se colocadas lado a lado com aqueles, ou seja, a diferenciação fálica foi abalada.

Kehl (1996) toma emprestado de Freud a expressão "narcisismo das pequenas diferenças" e constata que os homens parecem ser os mais afetados pela interpenetração de territórios, na medida em que isto vem colocando a identidade masculina em questão. Enquanto a mulher tem se movimentado na direção de conquistar atributos ditos "masculinos", o homem vem se sentindo ameaçado pela feminização, pela perda de seus atributos fálicos.

Roudinesco (2003), em seu livro A família em desordem, discute a queda progressiva da soberania divina do pai na família ocidental, nos dois últimos séculos, basicamente, pela irrupção do feminino. A autora se pergunta se estaríamos "assistindo ao nascimento de uma onipotência do materno que viria definitivamente aniquilar o antigo poder do masculino e do paterno em benefício de uma sociedade comunitarista ameaçada por dois grandes espectros: o culto de si próprio e a clonagem" (Roudinesco, 2003: 12).

Birman (2006) nos lembra que existem dois paradigmas nos textos freudianos que podem ser de auxilio na questão que pretendemos aqui tratar. $\mathrm{O}$ primeiro paradigma, coerente com a tradição patriarcal, aponta para a figura do masculino na origem e como signo de perfeição. $\mathrm{O}$ segundo paradigma, enunciado em seus últimos trabalhos sobre a feminilidade, aponta para o feminino na origem, articulado à castração. Sendo assim, "neste contexto, as figuras do masculino e do feminino seriam defesas articuladas em torno do falo contra a feminilidade originária, de maneira que a feminilidade estaria no fundamento do erotismo e seria a forma básica de subjetivação" (Birman, 2006: 309). Diante da necessidade de superar a importância conferida ao falo pela sociedade patriarcal, diante da minimização das diferenças, os lugares ocupados, as demandas e as ilusões de homens e mulheres sofreram relevantes modificações.

Desde os primórdios do Brasil colonial, o modelo de família patriarcal se impôs, determinando um vínculo homem-mulher no qual estava implícita uma 
relação de poder. De uma maneira geral, a mulher vivenciava a submissão presente nesta relação sem grandes conflitos, pois, ao lugar de esposa/mãe era atribuído um valor especial. Aquelas que, por alguma razão, não correspondiam a este modelo eram caracterizadas como "anormais" ou marginalizadas socialmente.

$\mathrm{Na}$ contemporaneidade, há uma exigência de igualdade que se reflete em um determinado tipo de discurso cuja expectativa é a de atingir um certo grau de liberdade individual, manter as relaçôes conjugais justificadas apenas pelo prazer e pela busca da perfeição, seja ela definida em caráter individual ou conjugal. Entretanto, nos confrontamos com as dificuldades dos parceiros em lidar com as imperfeições da vida cotidiana e com traços arcaicos de uma antiga dependência de natureza infantil (Lemaire, 2008). Percebe-se claramente uma ambivalência entre o discurso social assumido pelos cônjuges e os sofrimentos revelados na clínica com casais.

Farias e Barros (2003) observam que, no contexto atual, emerge do lado da mulher uma insatisfação expressa muitas vezes numa fala na qual se reclama de "uma falta de homens". Discurso que revela, ao mesmo tempo, desde um ressentimento até um antagonismo agressivo diante daqueles. Podemos nos questionar aqui acerca de que homem se está tratando. As constantes queixas são freqüentemente decorrentes da percepção da falta de potência fálica do companheiro, tal como percebida no fragmento clínico mencionado no início do texto.

Birman (2006) acentua que o preço pago pelas mulheres, ao longo do século XIX, com as restrições impostas ao seu erotismo provocou o incremento de perturbaçôes psíquicas como a histeria e o masoquismo. A figura da histérica revelava a rebeldia feminina diante de sua restrição à condição materna. $\mathrm{O}$ autor compara a imagem da histeria na época a outras figuras sociais como a prostituta, a infanticida e a ninfomaníaca que, igualmente, eram emblemáticas da resistência feminina.

Parece que hoje nos defrontamos com um outro tipo de resistência diferente daquela da histérica do início do século passado, diante das restrições ao seu erotismo. No caso das mulheres em terapia de casal descritas acima, o desejo sexual, claramente manifesto, encontrava por parte de seus companheiros uma resistência. Chamá-las de "gorda" era a "arma" utilizada para se contrapor ao desejo de suas parceiras, que se afirmavam enquanto sujeito. Tal qualificação teve como efeito uma desqualificação das mesmas como uma mulher objeto de desejo. Portanto, ao se colocarem como sujeitos desejantes, automaticamente perdiam a possibilidade de serem objetos de desejo, para aqueles homens.

Lembremos que Eiguer (1995), ao revisar o sadomasoquismo sob a perspectiva de investimentos narcísicos e libidinais, demonstra o quanto, no investimen- 
to narcísico, o sadismo faz intervir o desejo de atingir e desestruturar o narcisismo do outro.

Segundo Kehl (1996) o homem ainda pode privar a mulher e não se imagine que o faça "(apenas) por cálculo vingativo. É que ele não consegue reconhecer esta mulher tão parecida consigo mesmo, na qual também odiaria ter que se reconhecer" (Kehl, 1996: 26). Retornamos, aqui, às reaçôes masculinas diante da própria feminilidade para considerar que, nos casos citados, a perda de referências fálicas, além de se constituir em uma ferida narcísica para aqueles homens, também os desqualificou aos olhos de suas parceiras. Para a autora, o homem só se pergunta "o que quer uma mulher?" quando a certeza viril que o sustenta é questionada ou quando entra em crise por uma falha em seu processo desejante. Entretanto, o que o homem quer de uma mulher é que ela queira ser objeto de seu desejo. Neste sentido, a autora fica com a impressão de que os homens buscam encontrar numa mulher, ao mesmo tempo, uma disposição amorosa sem limites, submissa, passiva, aliada a uma capacidade de afirmar o próprio desejo e lutar por ele.

Nas situações clínicas relatadas, encontramos demandas contraditórias de ambos os lados. Enquanto mantiveram seus empregos ou um desempenho profissional satisfatório, os homens valorizavam os atributos fálicos de suas companheiras, acreditando que deveriam trabalhar e contribuir financeiramente para o pagamento das despesas familiares. Ao se sentirem desvalorizadas profissionalmente, elas passaram a ser percebidas como uma figura de mãe fálica, sádica, onipotente, que precisa ser destruída, humilhada. Neste sentido, nada mais eficaz que chamálas de "gorda" e apontar para uma incapacidade de suscitar o desejo de um homem. Quase como numa coreografia bem treinada, elas cresceram no desempenho do papel de mãe fálica, sádica e onipotente, alegando que já haviam esgotado todos os esforços para reconduzi-lo ao "bom caminho".

\section{ENTRE A COMPLEMENTARIDADE FUSIONAL E A AUTONOMIA}

O que leva um casal a se manter unido, quando a hostilidade e a violência estão permanentemente presentes em seu cotidiano? Lemaire (2008), em sua experiência clínica, relata sua dificuldade diante de parceiros que mesmo sofrendo juntos permanecem encerrados numa relação íntima marcada pelo ódio. O referido autor questiona-se sobre as motivações que mantêm uma relação marcada pela agressividade mútua, quando nada, aparentemente, impediria uma separação.

Willi (1985) entende que grande parte dos problemas existentes nas relações bipessoais é conseqüência de um jogo inconsciente, ao qual denomina colusão: jogo conjunto e não confessado entre dois parceiros, em função de um conflito 
similar e não superado, cujo caráter defensivo fixa cada sujeito em determinadas posiçôes e o impede de encontrar soluçôes para a crise na qual se encontra. Cada sujeito representa uma variante polarizada de um mesmo conflito, caracterizando uma reação neurótica recíproca. Imobilizam-se pela necessidade de manter no outro os aspectos rejeitados da sua própria dinâmica.

Segundo Berenstein e Puget (1993), os vínculos conjugais mais primitivos ou mais patológicos envolvem a noção de fusão, de idealização, a recusa das individualidades de cada um, e o desejo de um ser a imagem especular do outro, estabelecendo-se assim um tipo de dependência adesiva na qual a autonomia é inconcebível. A complementaridade entre os pares se coloca nessa etapa vincular, destacando-se o par amparador-desamparado, no qual os membros do casal mantêm-se fundidos, e os afetos são da ordem da violência, da irritação e da hostilidade. $\mathrm{O}$ projeto vital está sujeito a desacordos ou, ao contrário, a uma submissão total, com a transformação de um projeto a dois para o de um só. Quando a meta de um ego for a de transformar o outro em um complemento, anulando sua capacidade de pensar e de autonomia, poderá não ocorrer conflito. Contudo, as mensagens costumam ser contraditórias, produzindo uma relação baseada no enlouquecimento e confusão.

Gomes e Porchat (2006) também afirmam que muitas das escolhas conjugais buscam reparar o passado infantil e se configuram num tipo de vínculo de complementaridade assimétrica entre os parceiros.

A escolha inconsciente pode também buscar reeditar situações infantis negativas, repetindo-se então compulsivamente o conflito neurótico infantil, agora reencenado com o parceiro. Esse tipo de escolha conduz os cônjuges a formas de interação conjugal muito destrutivas, nas quais não há praticamente espaço para que o passado infantil seja reelaborado de modo mais positivo (Gomes \& Porchat, 2006: 147).

As autoras, tomando por base a teoria das relações objetais, apontam para o mecanismo de projeção intrínseco à constituição dos pares conjugais. A projeção de partes de si próprio no parceiro faz com que este, embora um objeto real, seja também um objeto fantasiado. O cônjuge é fortemente idealizado no início da relação e um conluio inconsciente é instalado. Com o transcorrer da vivência cotidiana, inicia-se o processo de "desidealização", existindo a possibilidade de saírem ou não desse pacto inicial e estabelecerem uma relação eu-outro na qual haja a percepção e o respeito pelas diferenças de cada um. Nas relações de casais mais primitivas ou menos maduras, tendendo à manutenção desses conluios, teremos o estabelecimento da fusionalidade. Na medida em que partes do próprio self 
são projetadas no outro, cria-se uma confusão entre o "sentido do self e o "sentido do outro", já que partes do self de um estão identificadas com partes do self do outro. Quando se leva essa dinâmica inconsciente ao extremo, pode-se dizer que cada parceiro não está se relacionando com o outro, mas consigo próprio no outro (Gomes \& Porchat, 2006).

Eiguer (1989) relata como é comum encontrarmos na clínica relações sadomasoquistas ou perverso-narcísicas, como o denegrir, mesmo que venha disfarçado sob o desejo altruísta de modificar o outro. As situações, anteriormente citadas, permitem entrever nos homens um forte desejo de vingança e, nas mulheres, uma desqualificação que toma ares de sadismo.

Analisando hoje algumas relações sadomasoquistas ou perverso-narcísicas, reconhecemos uma alternância de lugares que rompe estereótipos do passado. Estudos sobre violência doméstica costumavam apontar para a mulher e a criança como vítimas, enquanto o homem freqüentemente ocupava o lugar de algoz. Wang, Jablonski e Magalhães (2006) lembram que às características idealizadas atribuídas aos homens eram acrescidas algumas de cunho pejorativo, que os qualificavam de frios, insensíveis, agressivos, arrogantes, dominadores, autoritários, violentos e opressores. Entretanto, a partir da "minimização das diferenças", novos estudos apontam para uma alternância de lugares e para modificaçôes nas dinâmicas conjugais.

Pode-se dizer que o homem tem a força física, o poder econômico etc, mas a mulher também tem as suas armas e o seu poder. Muitas vezes ela usa a sua "fala" para provocar e ferir a virilidade do seu companheiro e a resposta dele, em geral, vem através da força física (Araújo, 1996: 13).

Neste estudo constatamos que muitos homens já não usam mais a violência física, mas especializaram-se, assim como suas parceiras, na utilização da violência psicológica. Como forma desesperada de defesa diante de uma desqualificação de suas imagens, homens e mulheres ferem com palavras. Afetado em seu narcisismo, o sujeito reage tentando denegrir o outro, alimentando a crise que os cônjuges, enquanto um casal, trazem ao consultório do analista.

\section{CONSIDERAÇÕES FINAIS}

A mulher contemporânea, de uma maneira geral, valoriza sua própria realização profissional e a de seu companheiro, mas abriu mão (voluntária ou 
involuntariamente) da fragilidade que demandava proteção e lhe era atribuída. Durante muito tempo foram alardeadas as ilusões mantidas pelas mulheres quanto ao que esperavam de um homem ideal; ou seja, deveriam ser provedores, fortes, competentes, companheiros, ótimos pais para seus filhos. Precisavam sentir-se protegidas, assim como esperavam proteção para sua prole. No geral, buscavam ser amadas e valorizadas, mesmo que a sexualidade ficasse em segundo plano. $\mathrm{O}$ homem, por sua vez, deseja salvar uma mulher, já dizia Freud ([1910] 1976). Se ela precisa dele e reconhece sua potência, seu lugar de "Sua Majestade" permanece garantido, mantendo-se a ilusão fálica.

No momento em que a mulher se assume enquanto sujeito desejante, torna-se mais exigente. Pode expressar seu desejo, mas espera poder manter-se como objeto de desejo de um homem. Homens e mulheres hoje, quando demandados sobre expectativas no casamento, costumam utilizar as palavras companheirismo e cumplicidade. Ao serem minimizadas as diferenças, poder-se-ia esperar algo próximo da realização destas expectativas. Entretanto, em relação aos casais mencionados, encontramos um ponto de impasse; os homens deixaram de se posicionar como sujeitos desejantes, deixaram de compartilhar com suas companheiras as ilusôes fálicas e passaram a depender delas para seu sustento econômico. É bem verdade que, em um primeiro momento, elas se mantiveram desejosas de lhes fornecer suporte emocional; contudo, a fragilidade exposta de seus companheiros, o jogo mãe dominadora/ filho apático que foi sendo estabelecido entre eles, fez reviver no discurso daquelas mulheres as antigas ilusões.

Nos casos clínicos em torno dos quais gira este artigo, houve uma perda das insígnias fálicas dos parceiros masculinos, provocando uma crise conjugal. Sabemos o quanto um investimento narcísico no outro é fundamental para a manutenção de qualquer relação. Porém estes casais nos fizeram refletir sobre como a própria fragilidade ou a do parceiro, principalmente a fragilidade do parceiro masculino, pode representar uma ameaça para a relação nos moldes da contemporaneidade. Os ideais de cumplicidade e parceria desaparecem neste contexto e a demanda feminina é a de que o homem recupere seu lugar fálico. $\mathrm{Ou}$ seja, um paradoxo se instala: a sociedade contemporânea propõe papéis igualitários para homens e mulheres, diferenciados do modelo tradicional de família. Contudo, a clínica com casais demonstra, em alguns casos, uma fixação do modelo "homem-ativo-fálico/mulher-passiva-castrada" que permanece, subjacente, à mudança dos tempos. 


\section{REFERÊNCIAS BIBLIOGRÁFICAS}

Araújo, M. F. (1996). Atendimento a mulheres e famílias vítimas de violência doméstica. Perfil - Revista de Psicologia, UNESP, Assis, 7-17.

Bauman, Z. (2004). Amor líquido: sobre a fragilidade dos laços humanos. Rio de Janeiro: Jorge Zahar.

Berenstein, I. \& Puget, J. (1993). Psicanálise do casal. Porto Alegre: Artes Médicas.

Birman, J. (2006). Arquivos do mal-estar e da resistência. Rio de Janeiro: Civilização Brasileira.

Eiguer, A. (1989). Le pervers narcissique et son complice. Paris: Dunod.

$$
\text { - (1995). O parentesco fantasmático. São Paulo: Casa do Psicólogo. }
$$

Farias, F. R. \& Barros, R. M. M. (2003). O ser mulher e as nervuras do social. Cadernos de Psicanálise, 19, 22, 187-210.

Freud, S. (1910). Um tipo especial de escolha de objeto feita pelos homens. Obras completas, ESB, v. XI. Rio de Janeiro: Imago, 1976.

Gomes, I. C. (2000). O trabalho, as diferenças de gênero e a dinâmica familiar. Mudanças: Psicoterapia e Estudos Psicossociais, 8, 13, 151-164.

Gomes, P. B. \& Porchat, I. (2006). Psicoterapia do casal. São Paulo: Casa do Psicólogo.

Kehl, M. R. (1996). A minima diferença. Rio de Janeiro: Imago.

Lemaire, J.-G. (2008). Comment faire avec la passion. Paris: Payot \& Rivages.

Roudinesco, E. (2003). A familia em desordem. Rio de Janeiro: Jorge Zahar.

Wang, M-L.; Jablonski, B. \& Magalhães, A. S. (2006). Identidades masculinas: limites e possibilidades. Psicologia em Revista, 12, 19, 54-65.

Willi, J. (1985). La pareja humana: relacion y conflicto. Madrid: Morata.

Recebido em 5 de janeiro de 2008 Aceito para publicação em 16 de junho de 2008 